\title{
Analysis of Moderate and Intense Rainfall Rates Continuously Recorded Over Half a Century and Influence on Microwave Communications Planning and Rain-Rate Data Acquisition
}

\author{
AUGUST BURGUEÑO, JOHN AUSTIN, ENRIC VILAR, AND MANUEL PUIGCERVER
}

\begin{abstract}
This paper is concerned with the statistical investigation of a massive data bank of 49 years of rainfall rate $R$ continuously recorded in Barcelona using a rain-rate gauge with ten seconds response time. With radio communications in mind, the paper addresses and reviews in detail: 1) reliable statistical model for $R, 2$ ) number of years required to obtain a database from which to derive a reliable $R$-distribution, and 3) the CCIR worst-month concept.

The research has shown that the generalized Pareto $a \exp (-\mu R) / R^{b}$ gives nearly perfect fit for all ranges of $\boldsymbol{R}$ followed closely by the gamma distribution, and the simpler square root $\left(R^{1 / 2}\right)$ normal distribution gives excellent fit too. The log-normal distribution was unsatisfactory for $R \geq$ $60 \mathrm{~mm} / \mathrm{h}$.

The spread of the yearly distribution of $P(R)$ is cube root normally distributed $\left([P(R)]^{1 / 3}\right)$ and between 7 and 10 years are required before a reliable average distribution $P(R)$ can be obtained. The study of the $P(R)$ return time in years is also presented.

High resolution of $P(R)$ is presented looking at the evolution of the annual $P(R)$ in terms of the hourly and monthly contributing parts revealing statistical features such as the location in time of rain rates above $50 \mathrm{~mm} / \mathrm{h}$. Finally, the study shows that the calendar month contribution to $P(R)$ remains at all times well below the synthetic CCIR worst month and recommendations are then given about its use.
\end{abstract}

\section{INTRODUCTION}

T recent years the increased congestion of the I communications spectrum coupled with the requirement for greater bandwidth have brought about an increasing need for the use of the short centimeter and millimeter-wave parts of the spectrum in both terrestrial and satellite communication paths. Although the importance of rain as the main attenuation factor in the microwave radio links has been recognized for decades, it is more recently with the single- and dualpolarization use of frequencies above $10 \mathrm{GHz}$, particularly for satellite communications, that the various aspects of the precipitation have been looked at in greater detail mainly by telecommunication administrations.

Although the specific attenuation $\gamma$ has been well estab-

Paper approved by the Editor for Computer-Aided Design of Communcation Systems of the IEEE Communications Society. Manuscript received September 5, 1985; revised July 12, 1986.

A. Burgueño and M. Puigcerver are with the Department of Atmospheric and Terrestrial Physics, University of Barcelona, Avenida Diagonal 647, Barcelona, Spain.

J. Austin and E. Vilar are with the Department of Electrical and Electronic Engineering, Microwave, Telecommunications and Signal Processing Research Group, Portsmouth Polytechnic, Portsmouth, PO1 3DJ United Kingdom.

IEEE Log Number 8613159 lished to have the form $a R^{b}$ (e.g., [1]), where $a$ and $b$ are constants function of the frequency and $R$ is the rainfall rate or intensity usually given in $\mathrm{mm} / \mathrm{h}$, the fact remains that $R$ is itself a random process and therefore $\gamma$ is a random process too. In addition, to get the total attenuation, we will have to multiply $\gamma$ by an effective rain-cell length $L(R)$ which is not only a function of $R$ but in general will be a function of the elevation of the path. To complicate matters, both $R$ and $L$ are functions of the climatic conditions of the radio link.

The climatic distribution of the rainfall intensity $R$ has naturally attracted a great deal of attention-for instance, Crane [2] has proposed a global rain rate climatic division with 8 zones, combining the empirical approach of Rice and Holmberg [3] with climatological data, satellite cloud data, and microwave radiometeorlogical observations. This followed earlier efforts of Dutton and Dougherty [4], [5] to produce detailed maps of precipitation rate $R$ for Europe and the U.S.

When it comes to designing a radio link, or even to contemplate the collection of data to study $R$, the fact still remains that $R$ is a random variable and some basic questions remain, to a great extent, unanswered. They include for instance:

1) the reliable statistical modeling of the distribution of $R$ for all ranges of $R$,

2) the number of years required to obtain a database from which to derive a reliable $R$ distribution,

3 ) is the CCIR synthetic worst month a good safe margin or is it an over-design criterion,

4) what is the conditional distribution of $R$ so that even after having exceeded a value $R$ yet the duration $D$ of the event lasts less than a specified lumber of seconds or minutes $D$.

Questions 1), 3), : ind 4) have a direct impact in radio links whether terrestrial or satellite, where the attenuation and cross polarization are high if the intensity of rain is also high (ice depolarization apart). Also questions 3) and 4) are concerned directly with the over design or not of the communications system in terms of link availability.

This paper presents the analysis of a massive data bank of 49 years of continuous recording of $R$ in Spanish Catalonia and addresses questions 1)-3). The rain gauge was of the Jarditype and has about $10 \mathrm{~s}$ inherent time response (Appendix I). Because of the high degree of statistical reliability answers have been found for the above questions. The subject of question 4), intensity/duration, is currently under investigation.

The material of the paper is covered in four sections. Section II describes the experimental procedures for the 
generation of the data bank and in the Appendix, a brief description is given of the rain-gauge which appears not to be well known in literature of radio communications although it was designed back in 1921. Section III deals with the annual distributions, the modeling, annual spread, confidences margin, and return time. Thus questions 1) and 2) are addressed in detail. Section IV deals with aspect 3 ) of monthly distributions whether real or synthetic (CCIR worst month). Finally, Section $\mathrm{V}$ is concerned with additional information which was possible to derive from such large data bank, namely contours of $R$ as a function of hour and month, etc. The study is mostly parametric but a great deal of effort has been put, whenever possible, to derive analytical expressions modeling the various results. Thus mathematical modeling of highly reliable statistical results is also a key feature of this paper.

\section{DATA BANK}

\section{A. Database}

Since 1927 and even during the Spanish Civil War a Jardí rain-rate gauge has been in continuous operation in the Fabra Observatory at an altitude of $413 \mathrm{~m}$ in the Tibidabo Mountain of Barcelona. It is because of the mechanical simplicity of operation of the gauge coupled with expectional careful attention that a full set of chart recordings of the intensity $R$ $(\mathrm{mm} / \mathrm{min})$ have been kept. The recordings investigated cover continuously 54 years from 1927 to 1981 . They have been digitized at the University of Barcelona and the results presented in this paper have been investigated jointly with Portsmouth Polytechnic at Portsmouth.

Each chart recording covers $24 \mathrm{~h}$, has a length of $26 \mathrm{~cm}$, and therefore $1 \mathrm{~min}$ is about $0.2 \mathrm{~mm}$ which in turn is about the resolution limit for manual digitization. The study has revealed that it rained on average 1.21 percent of the time each year. Therefore the total number of hours of rain digitized was approximately 5724 , equivalent to a length of $62 \mathrm{~m}$ of chart recordings. Irrespective of the resolution and skill in the digitizing process, the authors have measured the step response of the gauge which is $10 \mathrm{~s}$ (10-90 percent of the final value) and this gives confidence in the recording of very heavy rainfall of almost tropical nature which occur on the Catalonian coast (zone L CCIR [6]) with rapidly varying intensities and usually lasting only a few minutes.

The importance of the response time has been dealt with by several authors. Fig. 3 of [7] shows the impact using a fast response gauge of $10 \mathrm{~s}$ [8] as the integration time increases from $10 \mathrm{~s}$ to several minutes. Large rainfall rate events can be underestimated in their duration thus decreasing the cumulative probability $P(R)=\operatorname{Prob}\left(R^{\prime} \leqslant R\right)$. Clearly it is fortunate that the Jardí gauge had precisely about $10 \mathrm{~s}$ response time and thus the measured rates at Barcelona can be used with confidence. Similar impact of the response time of the instrument on the statistics of $R$ can be seen by inspection of Fig. 1 of [9] even though the times considered there were longer and ranging from 5 to $60 \mathrm{~min}$.

The lengthy digitizing process was carried out with great care by several students and researchers following as accurately as possible each one of the rain events. Computer generation of the chart recordings and comparisons with the original chart recordings was carried on a few occasions to check the digitizing process. The range $0-474 \mathrm{~mm} / \mathrm{h}$ in the charts was covered in steps of $6 \mathrm{~mm} / \mathrm{h}$ giving a total of 80 thresholds. The digitized values and the computed results (inclusive of corrections due to curvature of the trace, real zero, invalid records or events, etc.) were saved in files. Additional values entered included the type of precipitation and a total of 3633 data files were finally generated.

\section{B. Generation of the Data Bank}

As shown in Appendix $I$, the gauge should have a linear response (displacement of a float) as a first approximation for

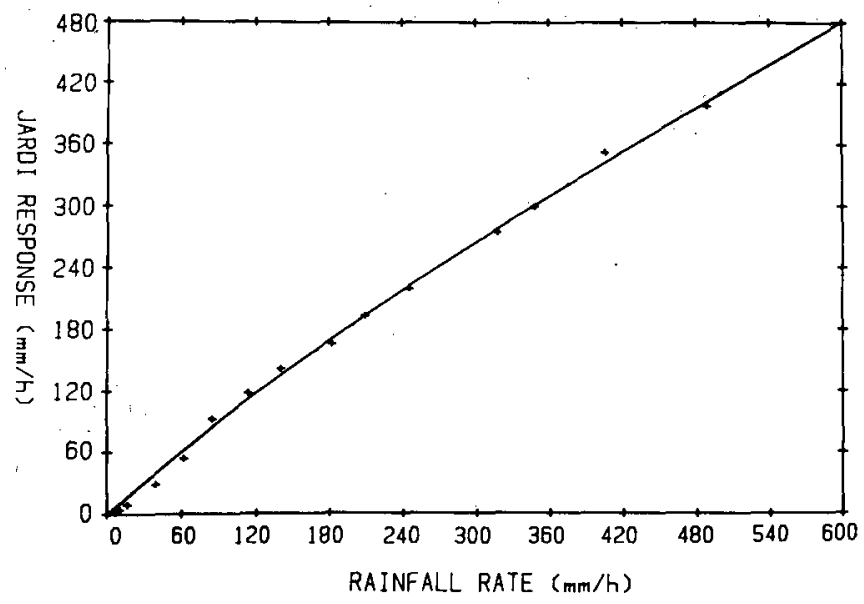

Fig. 1. Experimental calibration (crosses) and modeling of the response curve of the Barcelona Jardí gauge.

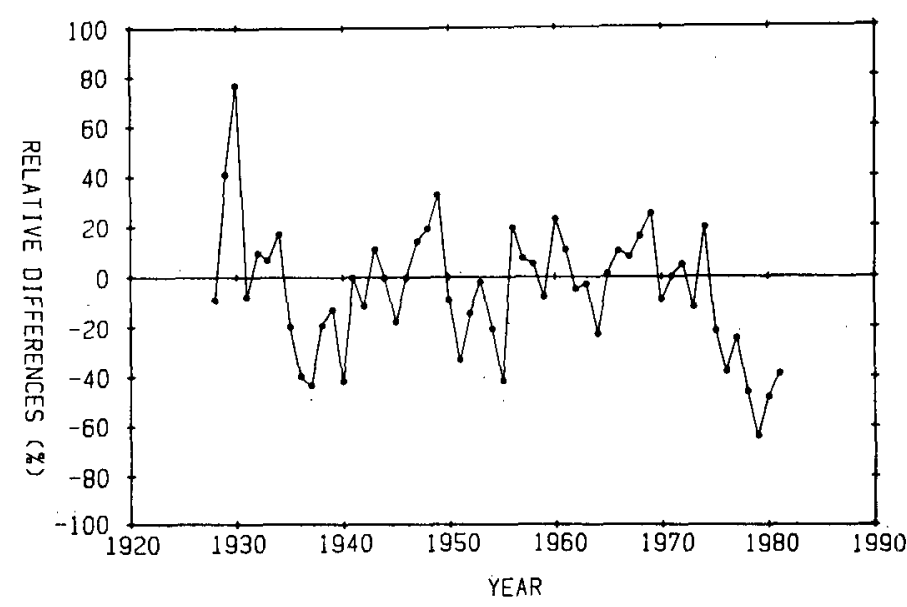

Fig. 2. Relative error between Jardí annual integration height and direct height.

moderate $R$, and this was confirmed during detailed experimental calibration. On the other hand the integrated value of the Jardí gauge over each year should agree within a reasonable margin of error with the annual rainfall amount recorded using conventional techniques. To convert the mechanical response to real precipitation rate $R$, the linear response was considered correct up to an $R$ of $73 \mathrm{~mm} / \mathrm{h}$ and the region beyond that was then approximated by a polynomial response. The experimental and best fit calibration curves are shown in Fig. 1. This calibration curve with the particular break point at $73 \mathrm{~mm} / \mathrm{h}$ was selected as the one which minimizes the difference between the annual amount directly measured by other instruments at the Observatory and the Jardí gauge. Fig. 2 shows the relative differences. The year 1930 was discarded as the difference is 77 percent. Also, 1978-1981 were rejected because the differences showed a trend to increase coinciding with the change in caretaker. ${ }^{1}$ Nevertheless, for completeness of the data bank, the cumulative distribution of these years is presented and included in Fig. 16. Thus, the final bank selected spans 49 years. One should notice that this cross-checking between the total rainfall and the integration of $R$ over the year is desirable and thus, although the shape of the distributions may be correct, the absolute numerical values can only be obtained in this way. One should also note that these differences are mostly due to

I The period 1978-81 corresponds to the change of caretaker at the Observatory who worked continuously there for over 50 years ensuring careful attention to the instrument, the serial number one of Richard of Paris. 
the low $R$ 's $(R \leqslant 50 \mathrm{~mm} / \mathrm{h})$ which contribute about 80 percent of the total annual rainfall.

The raw data can be arranged in several ways according to the type of study. The added periods of time that a given threshold $R$ of intensity is equalled or exceeded, $T(R)$, were divided by the various periods considered $D$ so that $T(R) / D$ would give elementary probabilities $P(R)$. The elementary periods $D$ considered were 1) month, 2) hour, and 3) hour month.

1) Monthly Basis: This is the most important as the CCIR recommends that annual distributions as well as the worst month are both generated from this base [17]. If $T_{i}(R), i=1$, $2 \cdots 12$, are the minutes per month, $i$, that the threshold $R$ has been either equalled or exceeded, then we have the 80 elementary probabilities (threshold levels of $R$ ) and associated base times.

$$
\begin{gathered}
P_{i}(R)=\frac{T_{i}(R)}{D_{i}} i=1,2 \cdots 12 \\
D_{i}=\left[\begin{array}{cc}
44640 \mathrm{~min} & i=1,3,5,7,8,10,12 \\
43200 \mathrm{~min} & i=4,6,9,11 \\
40320 \mathrm{~min} & \text { (or 41760 leap year) } i=2
\end{array}\right.
\end{gathered}
$$

In addition the yearly matrix of data of 80 rows and 12 columns is complemented with $P_{13}$ where $T_{13}(R)$ is given by the total time $\Sigma_{i=1,12} T_{i}(R)$ and where $D_{13}$ is either 525600 min of an ordinary year or 527040 for a leap year. Thus $P_{13}(R)$ is the conventional cumulative probability that $R$ can be either equalled or exceeded. Finally, and for a given year, the worst month distribution $P_{14}$ as recommended in [17] is given as the envelope of worst monthly probabilities. This is done by taking for each $R T_{14}(R)=\operatorname{Max}\left[T_{i}(R), i=1,2 \cdots 12\right]$ and as $D_{14}$ one takes the relevant month $i$ which gave the longest $T_{i}$ selected. In practice and for computer applications the data were arranged as 49 arrays of length $80 \times 14$.

Because of the large data bank for each $R$ and year considerd, the data $P_{i}(R)$ can be considered a sample value of the set of random variables $\left[P_{i}(R)\right]$. Also for each $i$, the 80 random variables are the discrete version of the continuous cumulative distribution probability $\operatorname{Prob}_{i}\left(R^{\prime} \geqslant R\right) \equiv P_{i}(R)$. This is why in Section III-B we carry out a statistical analysis of the ensemble of $P_{i}(R)$ with particular emphasis on $i=13$, the annual distribution.

2) and 3) Hourly and Monthly-Hourly Basis: With a large data bank it is possible to carry out a reliable study of the diurnal distribution of $R$ across the 24 h period over the whole of the 49 years, case 2 ), or even go to a higher resolution and consider the daily contribution to $P(R)$ for each calendar month [case 3)]. The result of these studies are given in Section $\mathrm{V}$ and the relevant probabilities are calculated in the usual way as the ratio between duration of "events" and period of time considered. In order to avoid too many points per day, the 24 hours (GMT) were divided into 12 periods of 2 hours each. This was found to give sufficient resolution and increased the reliability over a single $1 \mathrm{~h}$ interval.

\section{Annual Cumulative Distributions}

\section{A. 49-Year Average and Mathematical Modeling}

The 49-year average cumulative distribution

$$
\overline{P_{13}(R)}=\left(\sum_{j=1}^{49} P_{13}^{j}(R)\right) / 49
$$

has been plotted in Fig. 3, together with the average worst month $\overline{P_{14}(R)}$. Also shown is the modeling of $\overline{P_{13}}$ by the four mathematical models discussed below. The annual average has been limited to $10^{-4}$ percent, a value which corresponds to an accumulated duration of about $30 \mathrm{~s}$ in a year. Although the curve continues to increase monotonically well into $10^{-6}$ where the plot begins to flatten due to lack of data, it was thought more reliable to truncate $\overline{P_{13}(R)}$ to $\overline{P_{13}(R)} \leqslant 10^{-4}$ percent.

The study of the rain events has revealed that it rained on average 1.21 percent of the time over the 49 year period. Thus to convert the annual statistics of the figure to those under conditions of rain only, we must multiply the values by the factor $82.64=1 / 0.0121$ (e.g., [18]). This value as well as other parameters which characterize the distribution would naturally vary with climatic and geographical locations.

The modeling of the distribution of $R$ has attracted a great deal of attention in the past decade for obvious reasons of system planning. The literature survey points towards a general acceptance of the log-normal distribution, particularly in the U.S. Boithias, Lin, Fedi, and Segal among other investigators [18]-[22] have considered this distribution in detail. The gamma distribution appears to be more accepted elsewhere particularly by Morita [23] in Japan in order to model all ranges of $R$, even though Boithias [18], the CCIR [24] and De Reffye [25] recommend its use only for relatively high intensities of about $R>50 \mathrm{~mm} / \mathrm{h}$. This is why De Reffye has proposed a generalized Pareto distribution which approximates a log-normal distribution at low rates and a gamma distribution at high rates. This model would also include the power law proposed by Segal [22] for Canada.

In our investigation $\overline{P_{13}}(R)$ was modeled with four theoretical distributions: 1) log-normal, 2) square-root normal, 3) gamma, 4) generalized Pareto. The mathematical details and the numerical values of the parameters are given in Appendix 2. Fig. 4 shows the relative difference between the experimental average and the models. We conclude from the study that the Pareto distribution models the experimental curve well for both high and low intensities followed closely by the gamma distribution. Fig. 2 of [18] gives, for several locations in Europe, a table of values of the two parameters of a gamma distribution. The system designer is thus faced with the choice of either consulting the CCIR [24] and accept for his region the recommended values of $R$ which can be exceeded for the quoted percent of the time (year), or select a particular mathematical model. To do this, he must select the associated parameters (whether two or three) as well as find out the fraction of the time that it rains. If the mathematical modeling is the strategy selected, then in the light of the results of Figs. 3 and 4 it appears that the root normal offers both good simplicity and fit. Nevertheless the Pareto distribution appears to be gaining acceptance [26], [27].

\section{B. Spread of the Distributions-Modeling and Confidence Margins}

Because of the large number of years available, we can follow the strategy of Moulsley and Vilar [28] in the field of long-term scintillation statistics and group the yearly distributions in independent sets of several years. The aim is to observe the progressive clustering of the independent averages towards the final average of 49 years and thus obtain first a qualitative indication of the minimum number of years required for a reliable long-term distribution. Fig. 5(a) shows the family of 49 distributions. The averages are shown in Fig. 5(b)-(d) which contain, respectively, the average of 12 groups of 4 years each, 7 of 7 , and 4 of 10 . The progressive clustering of each of the independent groups towards a final distribution is an indication of the existence of a characteristic distribution of the region. In fact, the average distribution of the first 25 years and that of the second group of 24 years are very close even though they cover ranges in excess of $300 \mathrm{~mm} / \mathrm{h}$ and could be considered to represent periods about $1 / 4$ of a century apart. We see that 7 years is the minimum period to get a reliable statistic, but better estimations are obtained with an average of 10 years.

At this stage it is possible to give a numerical solution to this number of years required to get a reliable mean distribution. 


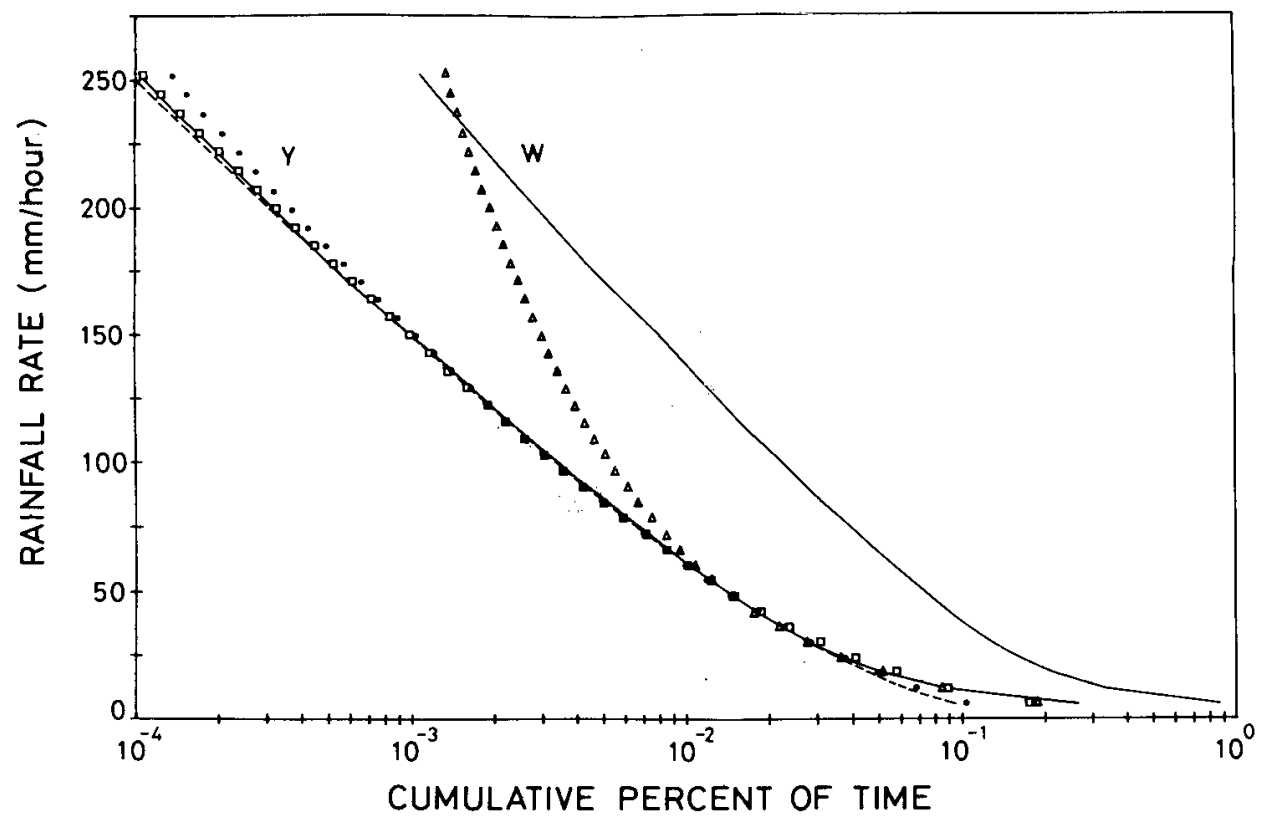

Fig. 3. The 49-year average annual distribution $\overline{P_{13}}$. Also shown worst month $\overline{P_{14}}$ and the modeling of $\overline{P_{13}}$ (see text) by: $(\Delta \Delta \Delta) \log$ normal, $(\cdots)$ ) square root normal, (--) gamma, $(\square \square \square)$ Pareto.

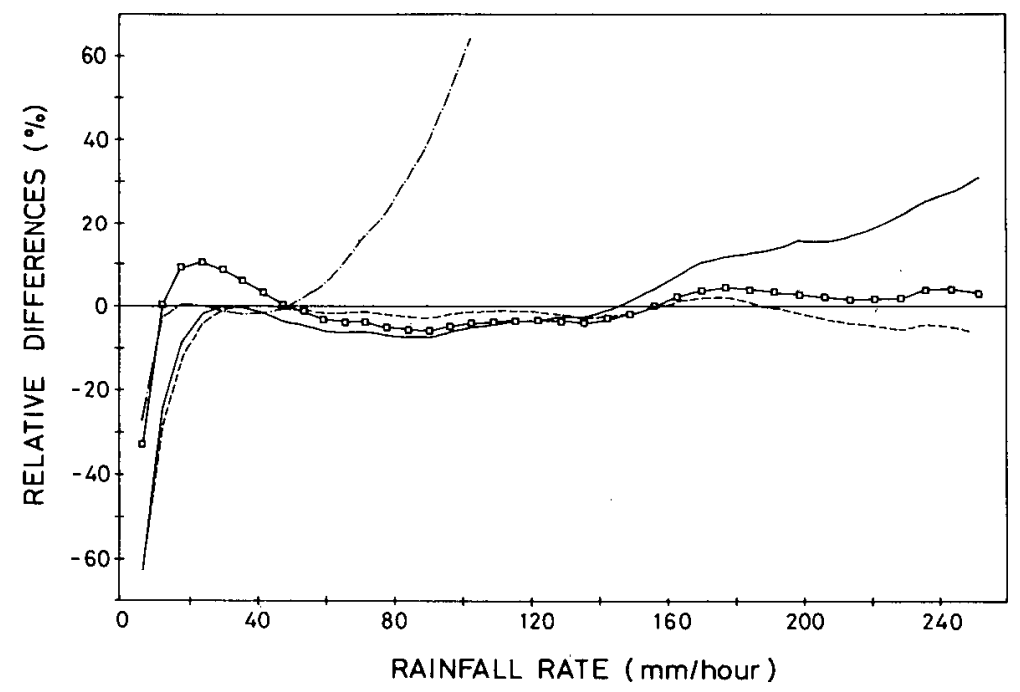

Fig. 4. Relative differences between $\overline{P_{13}}$ and the distributions of Fig. 3. $(-\cdot \cdot-) \log$ normal, $(\longrightarrow)$ square root normal, $(---)$ gamma, $(\square \square \square)$ Pareto.

By grouping the years (49) in sets of $N$ years we would get a family of means. This family of means, each of size $N$, constitute a population normally distributed. If we take the 595 percent probability interval (90 percent confidence limits), then this interval spread is given by $\overline{P_{13}}(R) \pm \sigma / \sqrt{N} \times 1 \cdot 64$ where $\sigma$ is the standard deviation of the original population of $P(R)$ 's and $\overline{P_{13}(R)}$ represents the 49 years average curve. (One should note that for this study the 49 years average had to be assumed the best estimate of the mean.)

The dotted lines in Fig. 5(c) and (d) show the 49-year 5-95 percent confidence limits of the mean and it is clear that whereas most of the 7-year averages fall within that range, all the 10-year averages fall within the range. One should also note that this range gives confidence in using 7 (or 10) years in estimating the 49 . We conclude that although 7 years is a minimum, 10 is desirable. The possible dependence or not of this criterion on climatic conditions and, hence, on the structure of convective precipitation extends beyond the intended scope of this analysis but the high degree of statistical reliability and independence of the group of observations points definitely towards a safe range of at least 10 years. This is in agreement with earlier remarks on this subject [21].

A numerical indication of the spread of the 49 values of $P_{13}(R)$ for each $R$ may be obtained from the standard deviation $\sigma\left(P_{13}(R)\right)$. Thus the coefficient of variation or index of spread is given by

$$
\text { C.V. }\left(P_{13}(R)\right)=\frac{\sigma\left(P_{13}(R)\right)}{\overline{P_{13}(R)}}
$$

and is shown in Fig. 6.

As expected from inspection of Fig. 5(a) the C.V. shows an 

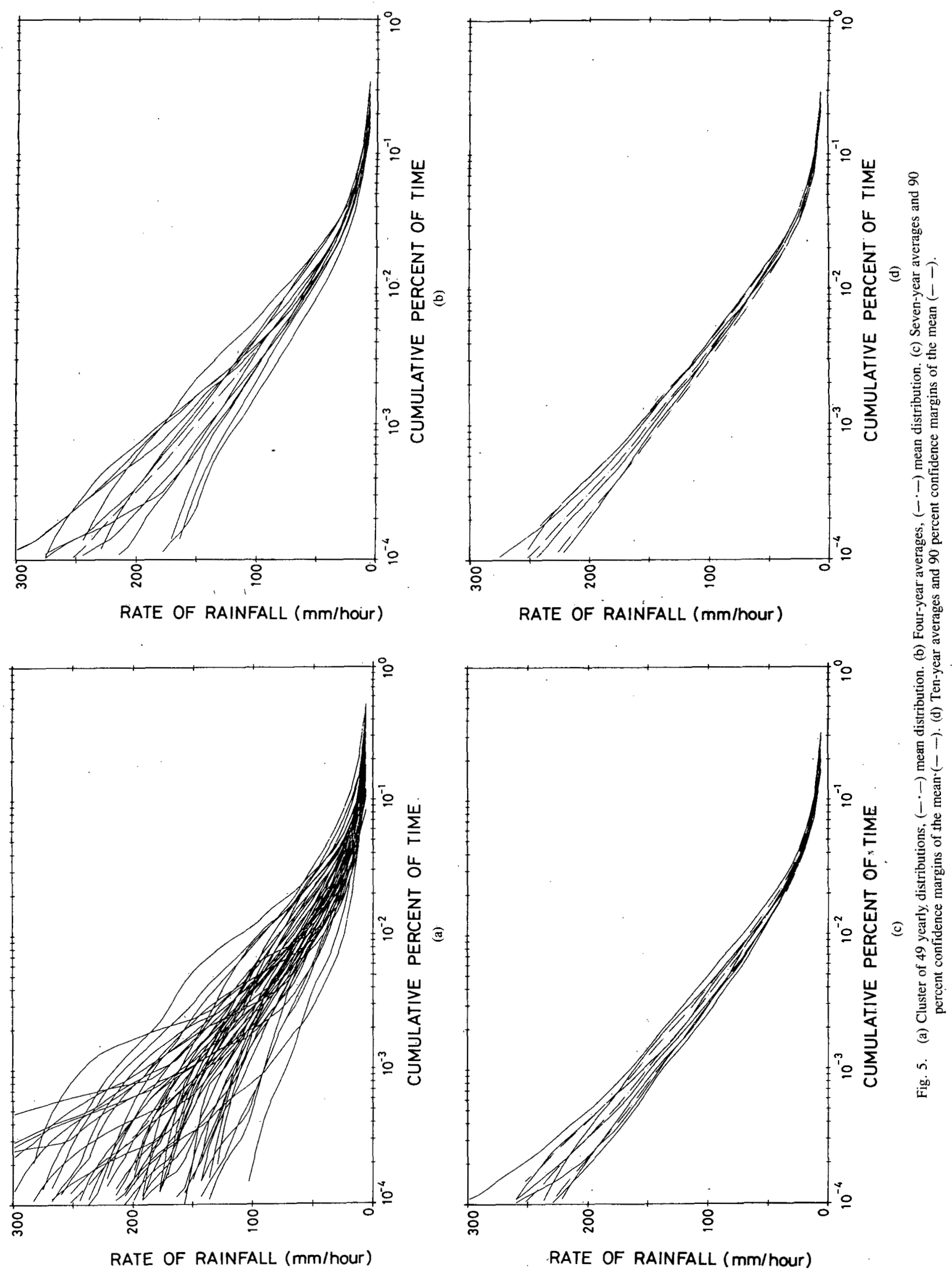


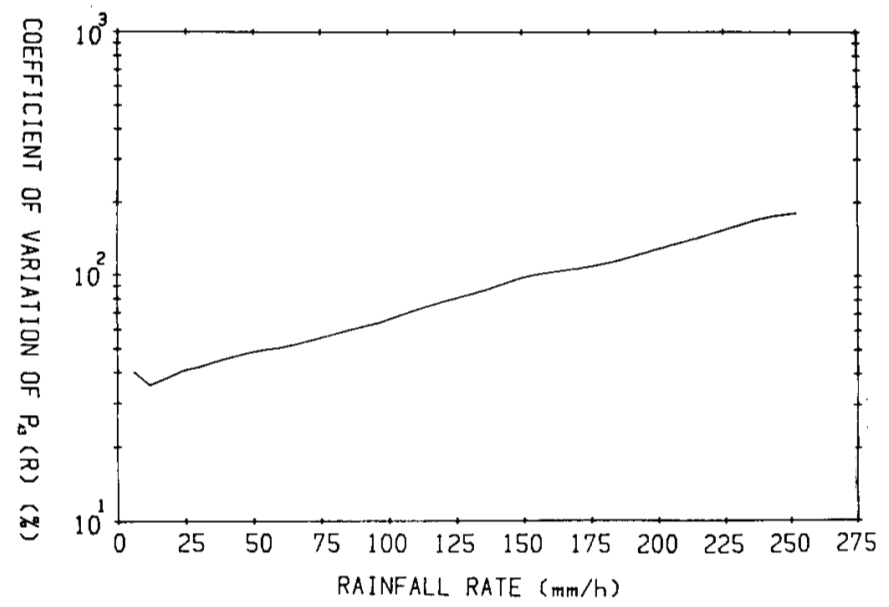

Fig. 6. Coefficient of variation of $P_{13}(R)$.

increase with $R$. It is linear in a logarithmic scale from about $12 \mathrm{~mm} / \mathrm{h}$ where we get 35 percent and increases to 100 percent at $150 \mathrm{~mm} / \mathrm{h}$ and to 200 percent at $250 \mathrm{~mm} / \mathrm{h}$.

The above study gives an indication of the magnitude in the spread of the values $P_{13}(R)$ (however reliable each one of the sample values might be). The question remains of the probability distribution or spread of these values. Are they normally distributed about some mean or are they mostly clustered around a median with tails in the distribution giving rise to the observed extreme distributions that one sees in Fig. 5 (a). The study of the probability density (histogram) of values of $P_{13}(R)$ as $R$ increases shows that for low $R$ 's ( $\leqslant 20 \mathrm{~mm} / \mathrm{h}$ ) the histogram has little skewness. However, for values of $R \geqslant$ $50 \mathrm{~mm} / \mathrm{h}$ the skewness becomes very significant and therefore most of the $49 P_{13}(R)$ values are clustered around some median. This is naturally quite convenient particularly for high rates $R$ and assists in the degree of reliability of $\overline{P_{13}}(R)$ for a given number of sample values. Fig. 7 shows a sample histogram for the case $R=48 \mathrm{~mm} / \mathrm{h}$. These histograms are obtained as we observe the distributions of the $P_{13}(R)$ by "cutting horizontally" for each $R$ in Fig. 5(a). The modeling of the distribution $F$, namely $F\left(P_{13}(R)\right)$ is important in order to give numerical values of confidence in statistical terms. For example, we may wish to determine for each $R$, the fractional number (probability) of estimates of $P_{13}(R)$ which will fall within a specified range of the median $\breve{P}_{13}(R)$. For this, the $F$ distribution

$$
F\left(P_{13}(R)\right)=\operatorname{Prob}\left(P_{13}^{\prime}(R)<P_{13}(R)\right)
$$

was investigated in detail. The models considered were the gamma distribution, the log-normal distribution and the cuberoot normal distribution all having a variable degree of skewness. The study was limited to $R<160 \mathrm{~mm} / \mathrm{h}$. Up to about $100 \mathrm{~mm} / \mathrm{h}$ the three distributions approximated the family of histograms with a good fit. Above about $100 \mathrm{~mm} / \mathrm{h}$ the log-normal distribution showed difficulty in following the experimental results. Finally, the cube root normal distribution was selected and checked with a Kolmogorov-Smirnov test. This distribution can be written as

$$
\begin{gathered}
F(X)=\int_{-\infty}^{X} f(X) \\
f(X)=\frac{1}{3 \sqrt{2} \pi X^{2 / 3} \sigma_{X}^{1 / 3}} \exp \left[-\frac{1}{2}\left(\frac{X^{1 / 3}-\overline{X^{1 / 3}}}{\sigma_{X}^{1 / 3}}\right)^{2}\right]
\end{gathered}
$$

where for each $R$ the random variable $X$ is in this case $P_{13}(R)$.

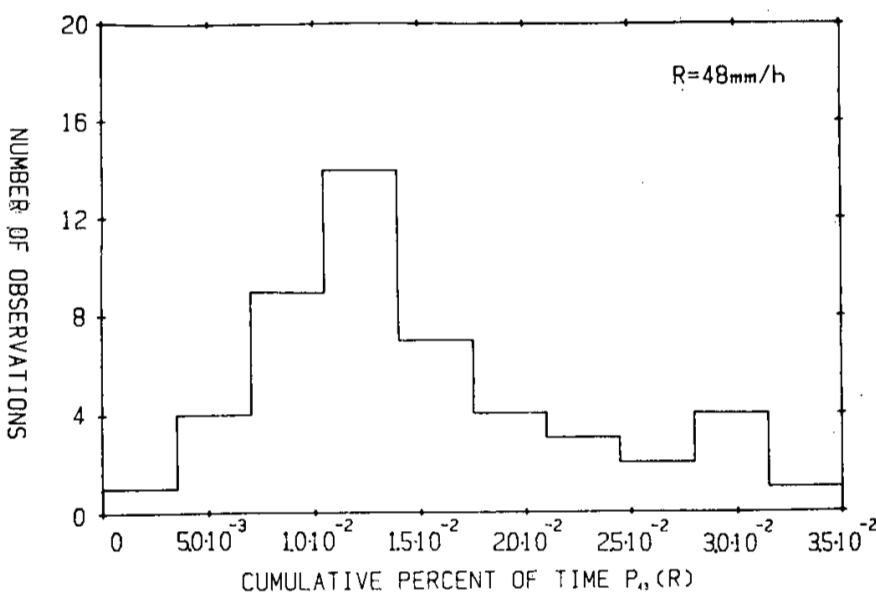

Fig. 7. Sample histogram of the spread of $P_{13}(R)$ 's for $R=48 \mathrm{~mm} / \mathrm{h}$.

The distribution (4) has also been used by Segal [22] for similar purpose. Fig. 8 shows the mean distribution of the 49 years and then for each $R$ we have plotted four selected values of the $F$ distribution thus generating the continuous curves. They are the median and plus or minus one and two standard deviations $\sigma_{X}^{1 / 3}$. One notices that because of the skewness, the average $\bar{P}_{13}$ and the median $\breve{P}_{13}$ of this distribution do not coincide. In other words $X^{1 / 3} \equiv \frac{\left(P_{13}\right)^{1 / 3}}{\equiv\left(P_{13}\right)^{1 / 3}}$. This is seen clearly for the specific case marked in Fig. 8 of $R=75$ $\mathrm{mm} / \mathrm{h}$. We see that on average this value will be exceeded $7 \times$ $10^{-3}$ percent of the year. Nevertheless out of the cluster of, say, 49 values, 50 percent of these would be below about $6 \times$ $10^{-3}$ percent and the other 50 percent would be above that value.

We can exploit further the distribution and again for $R=75$ $\mathrm{mm} / \mathrm{h}$ we see that $(84.1-15.9)=68.2$ percent of the population $P_{13}$ will have values ranging from $3.2 \times 10^{-3}$ to about $2 \times 10^{-2}$ percent. In other words, we can guarantee with probability 0.682 that the values $P_{13}(75)$ will be in that range. Something similar can be said for the range of spread $\pm 2 \sigma$ shown in the figure.

This interpretation of the $F$ probability leads immediately and naturally to another interpretation, that of the return time which some readers may find more useful, although it is basically another way of looking at the spread of $P_{13}$ 's.

The return time is described and defined in the following way. Given a limit $P(R)$ the question is how many years $N$ are required so that among them one satisfies $P_{13}^{\prime}(R)<P_{13}(R)$, and how many $N^{\prime}$ are required so that one of them satisfies $P_{13}^{\prime}(R) \geqslant P(R)$.

$N$ and $N^{\prime}$ are then given by

$$
N=\frac{1}{F(X)} \equiv \frac{1}{F|P(R)|}, N^{\prime}=\frac{1}{1-F(X)}
$$

and are known as return time (years) to a value smaller than $X(N)$ or larger than $X\left(N^{\prime}\right)$. Clearly only when the population of $P_{13}(R)$ has a symmetrical distribution we shall find $N=$ $N^{\prime}$. Because we know that $F(X)$ is skewed, therefore $N \neq$ $N^{\prime}$. Fig. 9 shows the average $\overline{P_{13}}$ and the associated return years. For example at $R=75 \mathrm{~mm} / \mathrm{h}$ and out of 10 years of observation in the long run we shall find one with a $P_{13}(75)<$ $2.6 \times 10^{-3}$ percent and one with a $P_{13}(75)>1.19 \times 10^{-2}$ percent.

The solution between the probabilistic and return time interpretation of $F\left[P_{13}(R)\right]$ is clearly a matter of choice and of physical insight into the spread of the population of annual cumulative values $P_{13}(R)$. 


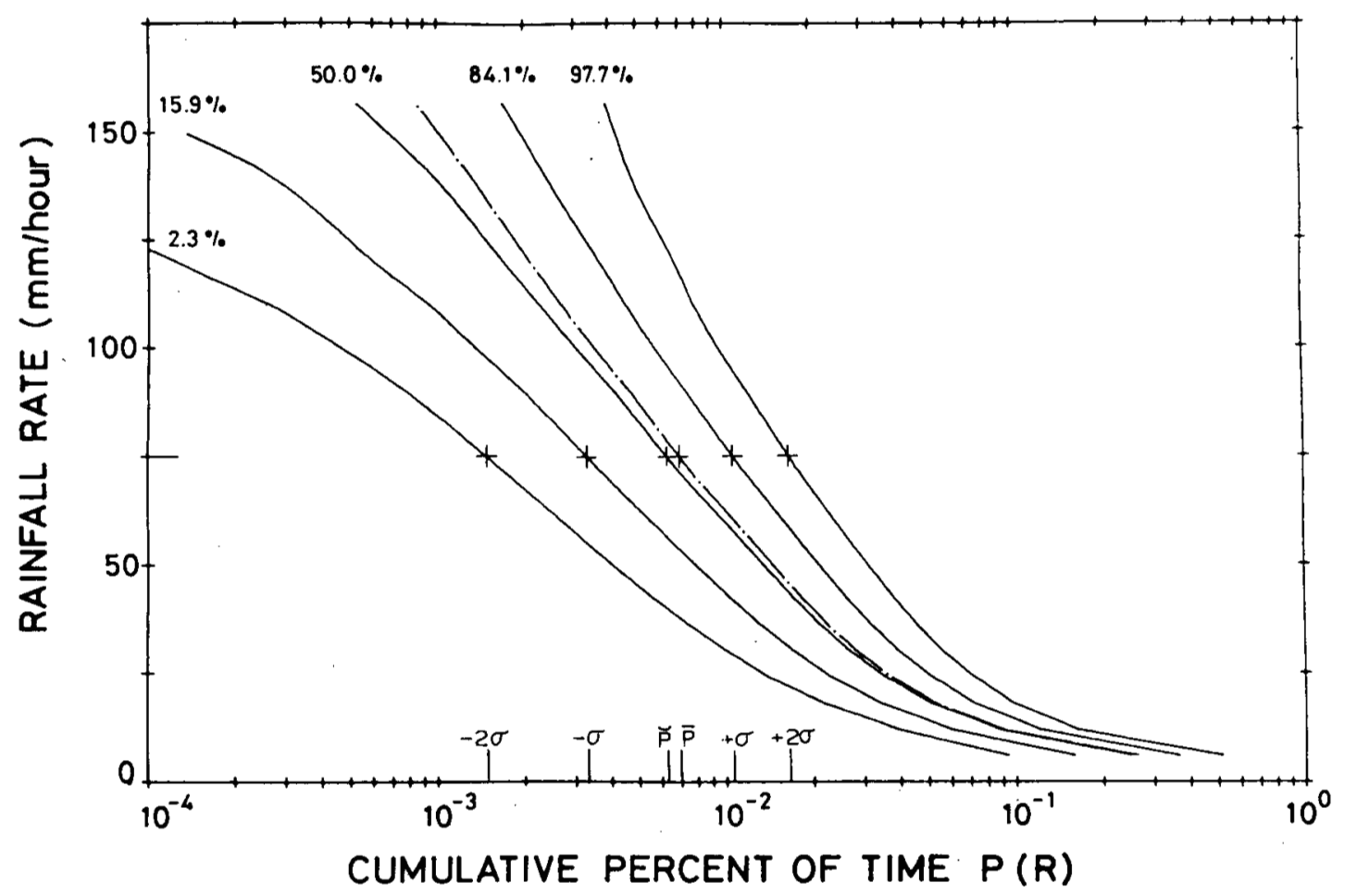

Fig. 8. Median of $P_{13}(R)$ plus or minus 1 and 2 standard deviations. (- - ) mean distribution.

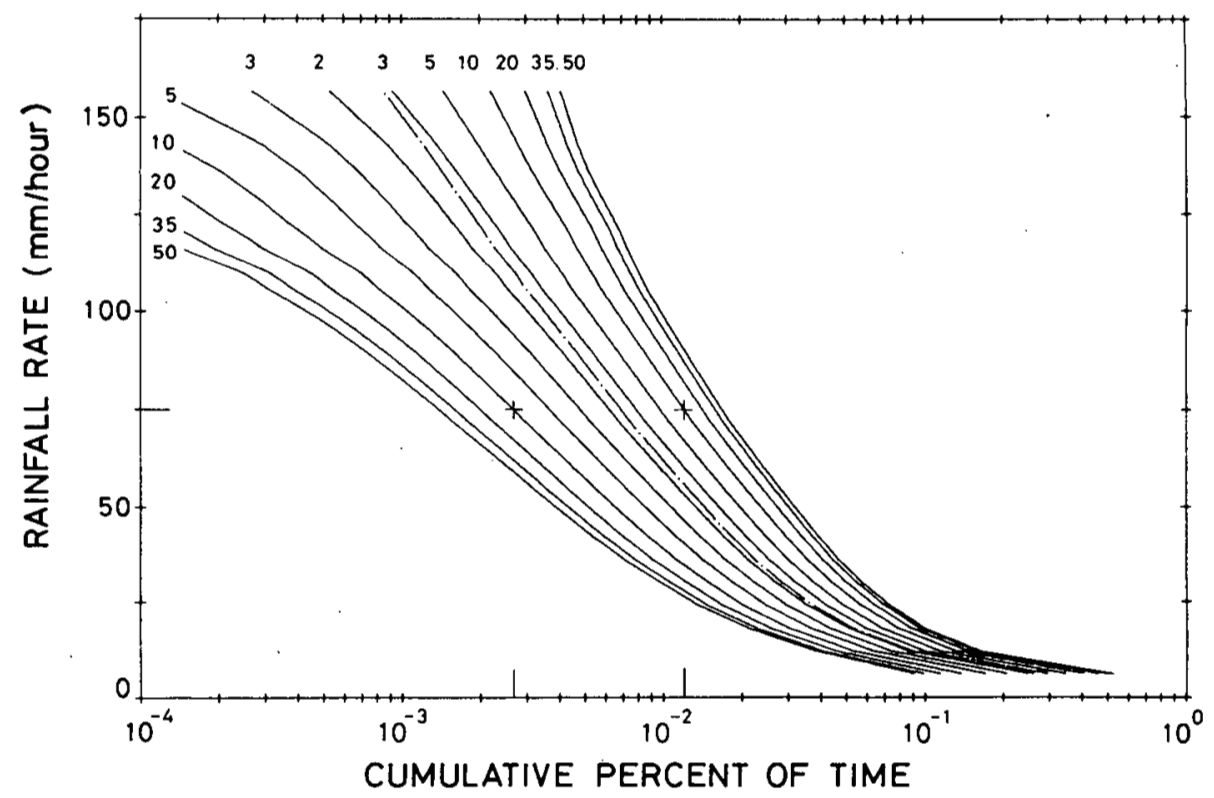

Fig. 9. Return times $N$ and $N^{\prime}$ in years to annual cumulative distribution values (see text). (-・-) mean distribution.

\section{MONTHLY Distributions AND WORST MONTH}

\section{A. The Worst Month and Relation to the Annual Distribution}

The worst month cumulative distribution as recommended by the CCIR [17] was introduced earlier in the paper as array no. 14 of the $P_{i}(R)(i=1,2 \cdots 14)$. The first 12 reflecting the monthly distribution. The average over the 49 years, $\overline{P_{14}(R)}$ was also plotted in Fig. 3. This worst month distribution is defined in [17] as that month in a period of twelve consecutive calendar months during which the selected threshold $R$ is exceeded for the longest time. The selection of the longest time implies that if for a given year we had 12 monthly distributions, (our set $P_{i}(R) i=1 \cdots 12$ ) we then select for each $R$ the month which exhibits the highest $P$. The selection on a monthly basis of this highest $P$ leads to a synthetic distribution which is an envelope of the monthly $P_{i}$ 's $(i=1 \cdots 12)$.

The necessity to account for extremes of probability has lead to an attempt to relate that synthetic worst month to the 


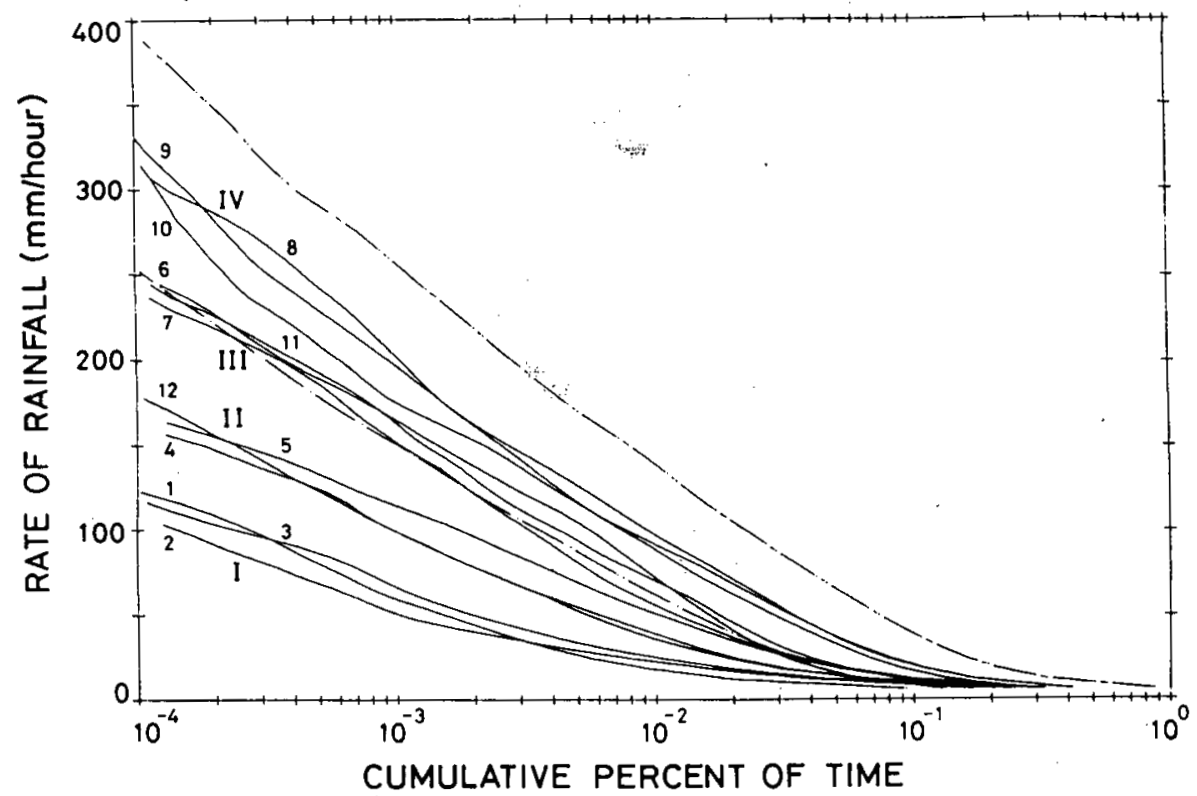

Fig. 10. The 49-year averaged distribution of months 1,2 , and 3 of group $I$, 4,5 , and 12 of group II, 6,7 , and 11 of group III and 8,9 , and 10 of group IV in relation to the annual $(-\cdot-)$ and worst month cases $(--\infty)$.

annual distribution by an expression of the type [17], [29]

$$
Q_{\mathrm{i} 4}(R)=\frac{\overline{P_{14}(R)}}{\overline{P_{13}(R)}}=A\left[\overline{P_{13}(R)}\right]^{b}
$$

and the result for the average over the 49-year period was $A=$ 1.3352 and $b=-0.1523$ with an excellent fit using a least squares technique. This leads to values of $Q_{14}$ ranging from 3.3 at $5 \mathrm{~mm} / \mathrm{h}$ to 10.5 at $252 \mathrm{~mm} / \mathrm{h}$ and this is in agreement with early results by some of the authors [30].

\section{B. Calendar Worst Month and Revision of the Worst Month}

Because of the somewhat artificial nature of the worst month concept, although one sees its necessity to account for extreme values of $P_{13}(R)$, is was decided to look in detail at the calendar months themselves and take advantage of the 49-year bank. Fig. 10 shows the interesting results. Group I contains the months of January (1), and February (2), and March (3). Similarly groups II, III, and IV contain the average of months $(4,5,12),(6,7,11)$, and $(8,9,10)$, respectively. The figures show also $\overline{P_{13}(R)}$ and $\overline{P_{14}(R)}$ so that we can examine how they fit in relation to the 49-year average and worst month distributions.

The selection of the months in groups which have similar distributions is naturally very dependent on the climatology of the area. Nevertheless the feature emerges that the worst real months (group IV in our case) are always better than the worst month by a factor ranging from about 2 , for $6-100 \mathrm{~mm} / \mathrm{h}$, up to 5 for the $100-250 \mathrm{~mm} / \mathrm{h}$ and we conclude that given a sufficiently large data bank, over design in time outage can be avoided by judiciously looking at calendar months which exhibit similar long-term distribution, as Fig. 10 shows. Naturally these "similar" calendar months may or may not agree with the average annual distribution $\overline{P_{13}(R)}$ as again the above figure shows.

Further insight into the extreme values of probability for safe link design might be obtained by looking at the evolution of the probability of occurrence of precipitation rates greater

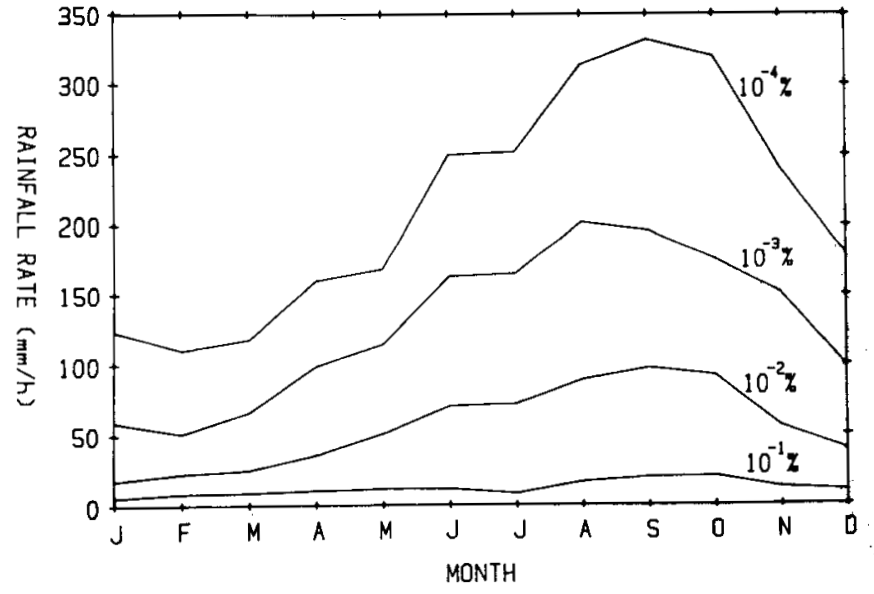

Fig. 11. Evolution of rain intensity throughout an average year for the indicated outage.

than about $50 \mathrm{~mm} / \mathrm{h}$ throughout the months of the year, and this was done although the results are not shown here.

Alternatively, we can look in detail at the evolution in the values of the intensity $R$, throughout the months of an average year, which is responsible for a specified outage (percentage of month that indicated $R$ is equalled or exceeded). The particular result of our investigation is shown in Fig. 11 where we clearly see the worst calendar months for a radio link as well as the optimum ones. However, if we are not concerned with extreme values $\left(P \geqslant 10^{-1}\right.$ percent $)$, then all months look equally favorable. Undoubtedly, similar investigation could be carried out for other CCIR zones provided that real monthly distributions can be obtained.

The study has also included for completeness the relation between the average annual $\overline{P_{13}(R)}$ and each one of the various $\overline{P_{i}}(R) i=1 \cdots 12$ as given by an equation of the form

$$
\overline{P_{i}(R)}=A\left(\overline{P_{13}(R)}\right)^{b}
$$

This is naturally convenient for our CCIR zone $L$ to where Catalonia belongs, but it will be of little use worldwide. 
TABLE I

VALUES OF THE PARAMETERS $A$ AND $B$ RELATING WORST MONTH AND MONLTHY DISTRIBUTIONS TO THE ANNUAL DISTRIBUTION (SEE (7) AND TEXT)

\begin{tabular}{|l|rc|}
\hline \multicolumn{1}{|c|}{ MONTH } & \multicolumn{1}{c|}{$\mathrm{A}$} & $\mathrm{b}$ \\
\hline \hline JANUARY & 2.5546 & 1.3512 \\
FEBRUARY & 48.6673 & 1.7028 \\
MARCH & 30.2329 & 1.5951 \\
APRIL & 5.9522 & 1.3011 \\
MAY & 11.2916 & 1.3180 \\
JUNE & 1.0146 & 0.9839 \\
JULY & 0.6842 & 0.9464 \\
AUGUST & 0.5503 & 0.8609 \\
SEPTEMBER & 1.3441 & 0.9372 \\
OCTOBER & 2.5737 & 1.0186 \\
NOVEMBER & 0.9247 & 0.9952 \\
DECEMBER & 3.5619 & 1.2405 \\
\hline WORST & 1.3352 & 0.8477 \\
\hline
\end{tabular}

Nevertheless, Table I summarizes these values of the parameters $A$ and $b$ of (7). This allows one to go from the average annual $\overline{P_{13}}$ to any average calendar month.

\section{Hourly and Monthly-Hourly Distributions}

Provided that the data bank is available, it will be undoubtedly. very useful to discriminate the yearly intensity outages $P_{13}(R)$ on the hour of the day inclusive (if possible) of the calendar month. This will permit to resolve which periods of the year contribute most to the small outages; in other words, we wish to find out the periods whose rain rate exceeds about $50 \mathrm{~mm} / \mathrm{h}$. This value is to be compared to the $40 \mathrm{~mm} / \mathrm{h}$ quoted in [3] and which other authors would also class as a limit for convective precipitation rate. This may be of particular importance to secure high density communications irrespective of the social or unsocial hours of the troughs of $P(R)$ for those seasons (months) when heavy showers may occur. A similar type of consideration could come in the field of civil works and drainage when dealing with heavy storms.

As explained in Section II-B, the hourly evolution of $P(R)$ was investigated looking at periods in the day of two successive GMT hours, and then counting the duration of exceedance of the given 80 thresholds. This was done either over the 49-year period, or going further and according to the month of the year (over the 49-year period) looking in detail at the plots $R-P_{13}(R)$ over two-hour periods. For the first type of investigation, the $12 R-P(R)$ distributions were looked at in detail against the annual average. The plots look similar to those of Fig. 10 in the sense that some distributions are above the annual average and others are below. Alternatively, and without selection on month or season, we can look at the evolution of $R$ throughout an average day for each outage selected. This is shown in Fig. 12. Here we see the impact of convective rain contributing mainly to the small percentages of time. We see for example that low values of $R$ are completely independent of the hour of occurrence (as was the case in Fig. 11 for the month of the year) whereas for very small percentages of time, values of $R$ in excess of about $150 \mathrm{~mm} / \mathrm{h}$ are very dependent on the time of day (as again it was in Fig. 11 for the month of the year). We see the particular feature that these very heavy rates are produced in the evening or early hours in the morning. As shown by Fig. 12, some months do not exhibit high values of $R$ even for low outages and therefore the statistics of Fig. 12 are smoothed out by this effect in the sense that maxima and minima (troughs) are contributed

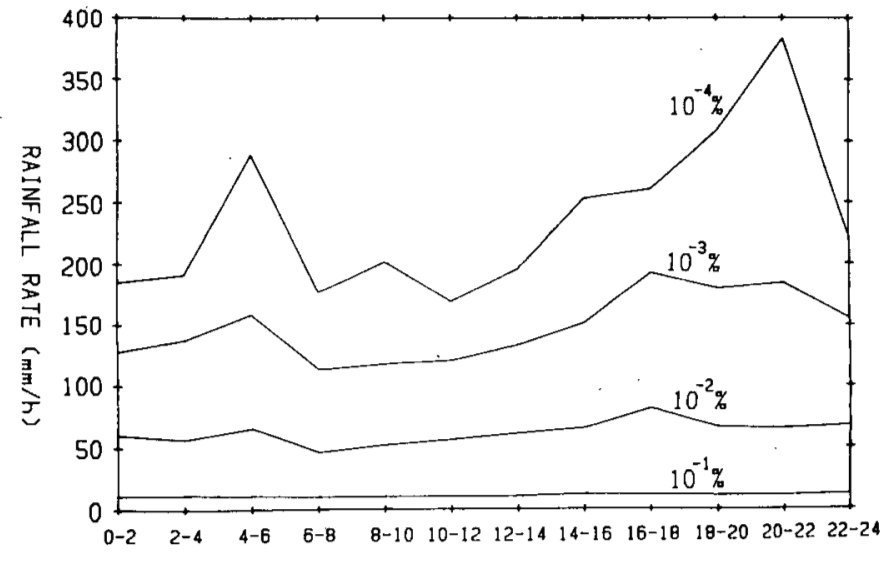

GMT (h)

Fig. 12. Evolution of rain intensity throughout an average day (over 49 years) for the indicated outage.

equally by months either with or without convective (heavy) precipitation.

The above study leads naturally to resolving the hourly evolution of $P_{13}$ in terms of the month over the 49-year period. In other words, we are lead to study Figs. 12 and 13 simultaneously and thus avoid the statistical smoothing due to those months with mostly low rain rate.

Unfortunately, we have now a four-dimensional problem; that is, for communication purposes, given a certain percentage of the year, the question is to determine the threshold $R$ responsible for this outage as month and time of the day go by. The massive data bank investigated in this paper has permitted to look at this in some detail, and two types of plots have been looked at. As there are 12 pairs of hours per day in a 12 month (year) period we have a total of 144 possible distributions.

The first type of result is illustrated in Fig. 13(a)-(d) which show in four 3-D plots the evolution discussed above. Naturally these results are typical only of the region considered (zone $L$ ) but they show for the indicated percentage of the average year the evolution of the features of Figs. 11 and 12 . Alternatively, and as shown in Fig. 14, we can plot the shaded contours which enclose precipitation rates exceeded. Here, the code for the grey level (and hence a given $R$ exceeded) will correspond to an annual outage which we can determine, for example, from Fig. 3. In agreement Figs. 11 and 12 we see again that $10^{-1}$ percent $(3.6 \mathrm{~min}$ in the $3600 \mathrm{~min}$ of a 30 -day month in an average year) 3-D plot hardly shows any heavy precipitation rate; the hourly evolution is practically constant for the months of August, September, and October. Similar features are exhibited by the $3 \times 10^{-2}$ percent. However, the $10^{-2}$ and $3 \times 10^{-3}$ percent 3 -D plots confirm that for the geographical zone studied, the light rain rates predominate in January, February, and March, that the important showery months are June, July, August, September, October, and November, and that for these six months the very heavy rain occurs mostly in the afternoon and then at night-and the early hours of the morning. Thus for example, and given the freedom of the time slot, we should plan any massive microwave communications data transfer for Catalonia in the morning.

\section{Discussion ANd ConClusions}

Because of the availability of nearly 50 years of continuous precipitation rate obtained with a rain gauge of $10 \mathrm{~s}$ of response time, this paper has investigated in detail several aspects associated with rain-rate data acquisition and related aspects of communication planning statistics.

The analysis of the average cumulative distribution of the 

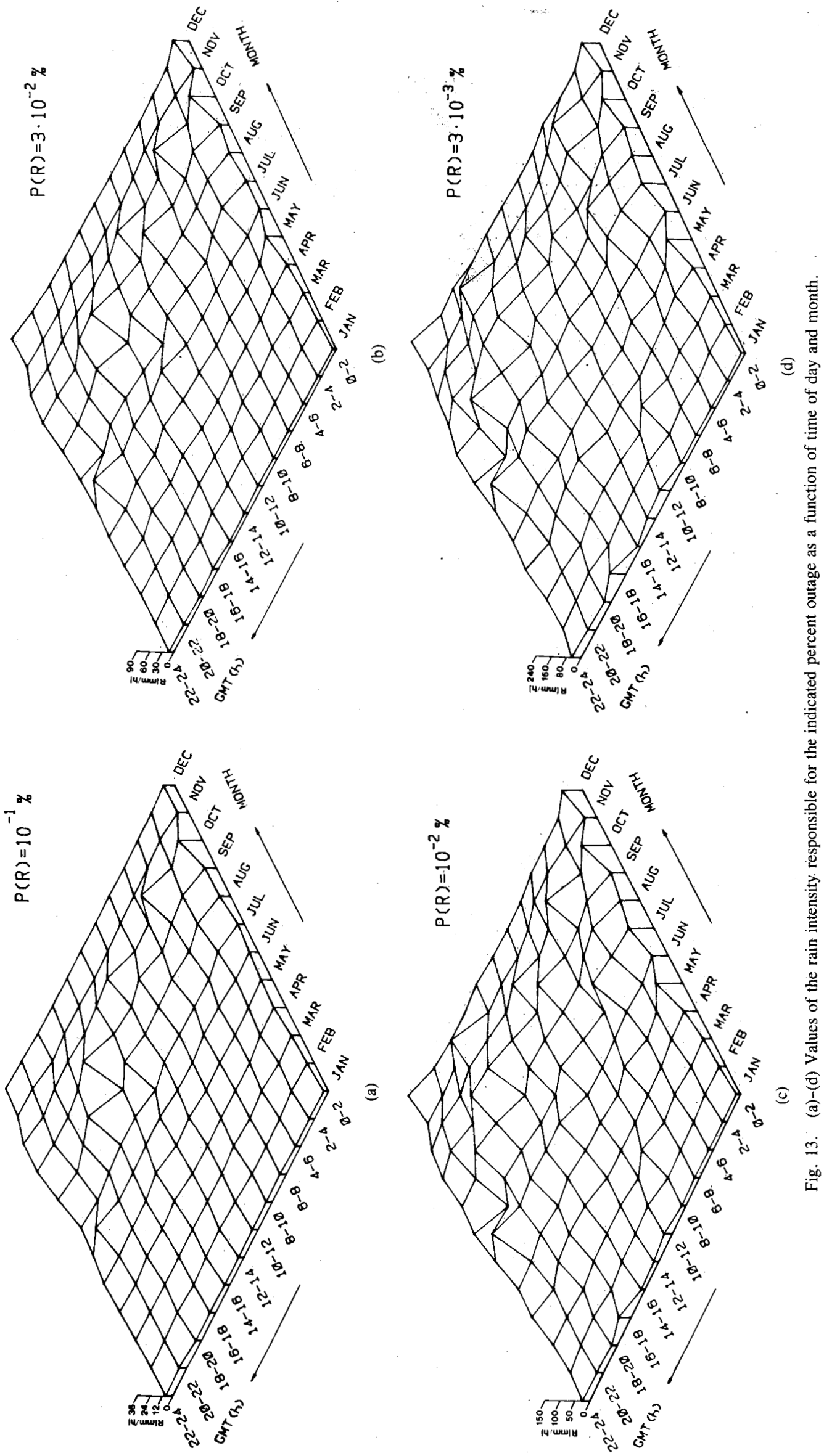
rainfall intensity over the 49-year period and which covers intensities ranging from a few $\mathrm{mm} / \mathrm{h}$ well into more than 150 $\mathrm{mm} / \mathrm{h}$, unusual in Europe but not in Catalonia, has shown that the modeling by a log-normal distribution is not suitable for precipitation rates above about $60 \mathrm{~mm} / \mathrm{h}$. The study of the gamma distribution extended the good fit into the high values of $R$ provided that $R>25 \mathrm{~mm} / \mathrm{h}$ confirming earlier findings by other authors. This is a limitation because regions like Europe often have rain rates less intense than this value. To get a better fit over the whole range, from a few $\mathrm{mm} / \mathrm{h}$ to well beyond the $250 \mathrm{~mm} / \mathrm{h}$, we require a three-parameter distribution such as the Pareto distribution investigated. An important result of this investigation has been to find that if we use as functional of $R$ the $\sqrt{R}$, then the normal distribution of $\sqrt{R}$ fits the experimental distribution very well within 10 percent up to $170 \mathrm{~mm} / \mathrm{h}$, and nearly to $250 \mathrm{~mm} / \mathrm{h}$ if we extend the tolerance to 20 percent of error (Fig. 4). This distribution is simple to handle and use and we would recommend it for serious consideration as an alternative model covering low and high $R$ 's. In order to extend or compare the specific numerical results of the cumulative probabilities for a given $R$ to other locations, one must bring in the average fraction of the time (year) that it rains. Our fraction was 1.21 percent.

Each one of the 80 chart threshold levels in which our $0-474$ $\mathrm{mm} / \mathrm{h}$ range was investigated, had an annual cumulative probability value (outage) $P(R)$ associated. There are 49 values (covering the period 1927-1981). This has permitted to address in detail the statistics of the spread of these $P(R)$ values. By averaging $P(R)$ in independent groups of an increasing number of years it has been found that no less than seven years, and preferably ten, are required before the various average distributions cluster towards a common final one (the one over 49 years) which naturally shall reflect the geographical location and zone. Furthermore, by investigating for each $R$ the distribution of the 49 values of the ensemble $[P(R)]$ it was found, in agreement with Segal of Canada, that these values had a cube-root normal distribution. This permitted establishing a parametric study of margins of statistical confidence (Fig. 8), and to determine return times to a $P(R)$ distribution greater than or smaller than some specified boundaries (Fig. 9). For example, the comparison between Figs. 8 and 9 show that the $+1 \sigma$ and $-1 \sigma$ spread of the distribution of $P(R)$ 's for $R=75 \mathrm{~mm} / \mathrm{h}$ corresponds (approximately) to a return time $N$ and $N^{\prime}$ of 6.3 years. If we extend the range to $+2 \sigma$ and $-2 \sigma$ then the return times become 44 years.

These results are vital to plan a campaign of rain-rate data acquisition with statistical criteria supporting the decision. Perhaps it is relevant here to bring in the consideration of balancing complexity of the gauge, its maintenance and data retrieval; there is no doubt that if the Jardí gauge had not had the characteristic of simplicity of maintenance and had it not been located in an observatory securing uninterrupted unskilled maintenance, the data bank would have had the usual problems of interrupted recording. The authors believe that the balance tilts in favor of continuous and reliable manpower irrespective of the level of skill and therefore the gauge must match the technical skill of the caretakers for long-term investigations over many years.

The study of the subject of the synthetic worst month recommended by the CCIR has been looked at in detail. Experience from previous work on the same subject shows that there is no difficulty in mapping the average annual. distribution to that of the worst month one via a relation of the type $A\left[\overline{P_{13}}(R)\right]^{b}$. However the worst month looks at extreme values of $P(R)$ irrespective of the time of occurrence and this is why in this paper a closer look was taken resolving the $P(R)$ in terms of its calendar month contributions. As a result it was found that several groups had an average $P(R)$ which was above the annual $P(R)$ and some others were below but at all times they were less than the $P(R)$ of the worst month by at least a factor of 2 and increasing to 5 for $R>100 \mathrm{~mm} / \mathrm{h}$. The recommendation therefore is that if the data bank is available, the calendar month distributions over the years should be closely investigated to avoid the risk of over-estimating outages and thus over-designing microwave radio-communication systems.

The investigation of the $P(R)$ for the various calendar months over the years reveals the importance of those months with a great probability of convective rainstorms (August, September, and October in our particular zone). This has led to investigating in detail the hourly evolution of $R$, given a specific outage, as time of day and month of the year go by. This study of the fine structure of $P(R)$ was carried out using both 3-D representation and contour plots (Figs. 13 and 14). The results, although only applicable to Catalonia and more generally to the northwest of the Mediterranean sea (zone $\mathrm{L}$ CCIR), indicate the power of this type of statistical analysis from which a radio-communications planning can now be undertaken with confidence.

\section{APPENDIX I}

\section{The Jardi Rain-Rate Gauge-Static Response and Calibration}

In the early 1920's, at the request of the Catalonia Local Authority and Meteorological Service, a rain rate gauge was designed by Professor R. Jardí for flood forecasting and civil works planning. The original description and basic operation can be found in [10]-[12]. The gauge, which is no longer manufactured, gives chart recordings of $R$ in $\mathrm{mm} / \mathrm{min}$ and was designed to monitor the intense precipitation rates which occur in the northeast of Spain. One should note that in civil works and Telecommunications what matters most is the rate of rainfall, and the Jardi gauge was the first rapid response rainrate gauge designed. Fig. 15 shows a diagram of the instrument. A very brief description of the instrument can be found in English in [13]-[16]. This instrument is still in operation at the Fabra Observatory, and operates in the following way. The rainfall collected by a large funnel of section $S_{o}\left(0.18 \mathrm{~m}^{2}\right)$ flows to a chamber where a float rises to a given level (response), due to the input flow (signal). As the float rises, the opening of variable area $\pi R^{2}-\pi r^{2}$ increases due to the conical shape of the stindle which blocks the orifice of radius $R$. This movement continues until input and output flows are equal and the movement of the float is recorded on a daily chart attached to a revolving drum. If $\phi$ is the input flow of water in, say, $\mathrm{cm}^{3} / \mathrm{min}$ then $\phi$ is given by the flow velocity $v$ $=\sqrt{2 g(h+a)}$ times the clearance $\pi R^{2}-\pi r^{2}$. We also note that $\phi$ is given by the product $p S_{o}$ where $p$ is here the rain rate in $\mathrm{cm} / \mathrm{min}$. One can easily show that if the stindle blocking the orifice has a conical shape so that the radius $r$ for a given position $h$ is given by $R(1-h / l)$, then we get the basic equations for the gauge relating the rain rate $p$ to the displacement $h$ (recorded)

$$
p=v_{o} \frac{S_{1}}{S_{0}} \sqrt{X+\bar{A}}\left[2 X-X^{2}\right] \quad 0 \leqslant X \leqslant 1
$$

with $X=h / l, S_{1}=\pi R^{2}, A=a / l, v_{o}=\sqrt{2 g l}$, and with $g$ the gravity acceleration constant. If we keep $l \gg h$ and $l \gg a$ so that the orifice is closed by the part of the stindle closest to the base of the cone, then $(\mathrm{A}-1)$ can be approximated by the relation

$$
p=2 v_{o} \frac{S_{1}}{S_{0}} \sqrt{A} X
$$

and thus we have a quasilinear relation $p=$ constant $h$. In 


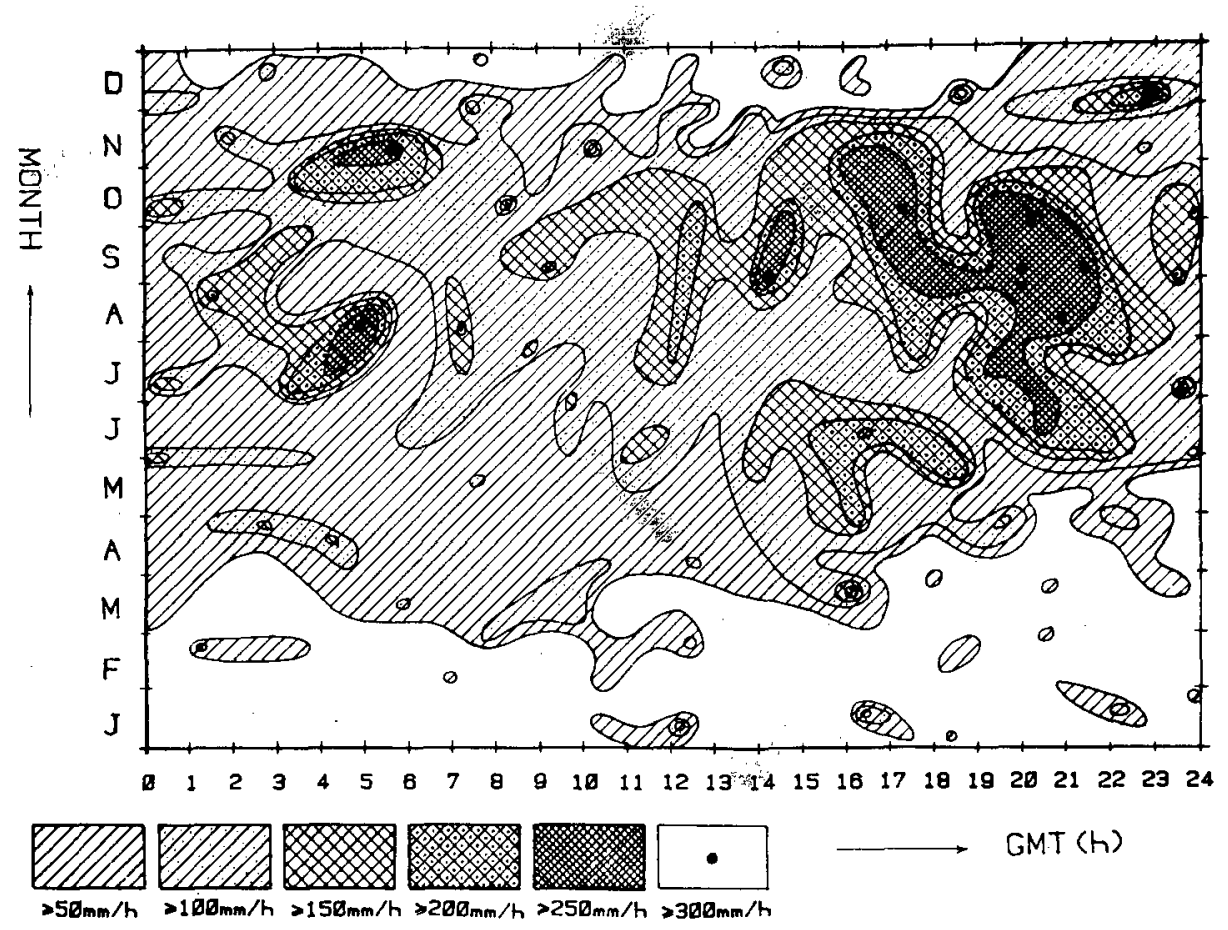

Fig. 14. Contour plots of rain intensity indicated as a function of time of day and month.

practice, one finds some slight curvature in the profile of the stindle to linearize the response as much as possible over a wide range of $p$. Because of its inherent nature of handling a noncompressible fluid, the gauge has a relatively rapid response. Tests carried out using carefully controlled simulated values of $p$ have shown that the Fabra Observatory gauge has just under $10 \mathrm{~s}$ response time to go from 10-90 percent of the final value after applying a step input $\Delta p$. To reach the final steady value we measured about $20 \mathrm{~s}$. One notices that the gauge operates as a mechanical control system in which the restoring force to a constant input flow $\phi$ is the difference between the buoyancy of the float and its weight (inclusive of any friction in driving the pen-recording mechanism).

\section{APPENDIX II}

\section{Modeling of the Average Annual Distribution}

The research in the mathematical modeling was carried out first by plotting the average annual cumulative distribution in its conventional form Prob $\left(R^{\prime}<R\right)=1-P(R)$ using probability paper. In abscissas, one plots the reduced variable (number of sigmas) and in ordinates a functional of $R$ (to be determined). In this way, $\ln R$ was found to be normally distributed for the range $12-60 \mathrm{~mm} / \mathrm{h}$. However, a better straight-line fit within the range $18-170.5 \mathrm{~mm} / \mathrm{h}$ was obtained using as functional of $R, \sqrt{R}$. The two distributions 1) and 2) in conventional outage form can be written as

1) Log Normal:

$$
\begin{array}{r}
P\left(R^{\prime}>R\right)=\int_{R}^{\infty} P\left(R^{\prime}\right) d R^{\prime} \quad R>0 \\
P(R)=\frac{1}{\sqrt{2 \pi} R \sigma_{\ln R}} \exp \left[-\frac{1}{2}\left(\frac{\ln R-\overline{\ln R}}{\sigma_{\ln R}}\right)^{2}\right]
\end{array}
$$

with $P(R)$ the probability density or frequency function distribution. By using $\overline{\ln R}=-6.538$ and $\sigma_{\ln R}=2.880$ (A21) was found to fit $\overline{P_{13}(R)}$ in the range $12-60 \mathrm{~mm} / \mathrm{h}$ with relative differences less than 10 percent.

\section{2) Root Normal:}

$$
\begin{gathered}
P\left(R^{\prime}>R\right)=\int_{R}^{\infty} P\left(R^{\prime}\right) d R^{\prime} \\
P(R)=\frac{1}{2 \sqrt{2 \pi} R^{1 / 2} \sigma_{R^{1 / 2}}} \exp \left[-\frac{1}{2}\left(\frac{R^{1 / 2}-\overline{R^{1 / 2}}}{\sigma_{R^{1 / 2}}}\right)^{2}\right]
\end{gathered}
$$

with now $\overline{R^{1 / 2}}=-23.225$ and $\sigma_{R^{1 / 2}}=8.325$. Good fit within the 10 percent exists well up to $170 \mathrm{~mm} / \mathrm{h}$.

3) Gamma Distribution: This distribution is favored for large precipitation rates. The technique to determine the distribution has been discussed elsewhere [18] by Boithias. By calling $X$ a convenient reduced variable $R / R_{o}$ he then finds the following approximation

$$
\begin{aligned}
P(x>X) & =\frac{1}{\Gamma(\nu)} \cdot \int_{X}^{\infty} e^{-t} t^{\nu-1} d t \sim \nu \int_{X}^{\infty} \frac{e^{-t}}{t} d t \\
& \simeq \nu \frac{c^{-X}}{X+0.68+0.28 \log _{10} X}
\end{aligned}
$$

An iterative technique gave $R_{o}=54 \mathrm{~mm} / \mathrm{h}$ and $\nu=5.7 \times$ $10^{-4}$ and the approximation to the experimental curve was within 10 percent provided that $R>24 \mathrm{~mm} / \mathrm{h}$.

4) Generalized Pareto Distribution: The distribution proposed by De Reffye [25] approximates a log-normal distribution at low rates and gamma distribution at high rates and includes the power law of Segal [22]. The distribution can be written as

$$
\begin{aligned}
P\left(R^{\prime}>R\right) & =\left(\frac{\alpha}{R}\right)^{\nu} \cdot \exp (-\mu R) \\
& =a \exp (-\mu R) / R^{b} \quad R>0
\end{aligned}
$$




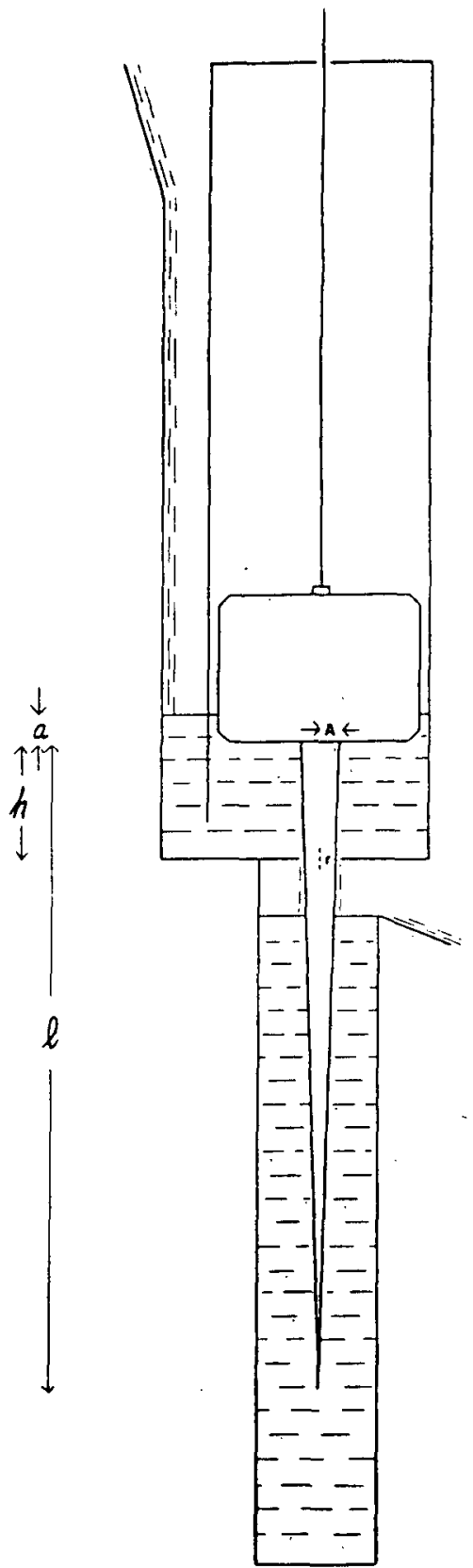

Fig. 15. Principle of operation of the Jardí rain rate gauge (to scale).

and fits our experimental $\overline{P_{13}}$ within 10 percent, well beyond $260 \mathrm{~mm} / \mathrm{h}$ provided that $R>12 \mathrm{~mm} / \mathrm{h}$. The constants found

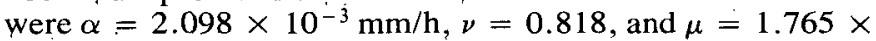
$10^{-2}(\mathrm{~mm} / \mathrm{h})^{-1}\left(a=8,418 \times 10^{-3}, b=0.818\right)$.

\section{APPENDIX III}

As explained in the text, for reasons of homogeneity, the years 1930 and 1978-1981 were excluded from the overall analysis in light of the comparison and discrepancies shown in Fig. 2. Nevertheless, Fig. 16 shows the five cumulative distributions of those five years, and they have been included in this paper for the sake of completeness and possible reference.

\section{ACKNOWLEDGMENT}

This paper is part of a cooperative venture between Portsmouth Polytechnic and the University of Barcelona and several organizations have contributed to its success. The Barcelona group is grateful to the CIRIT of the Generalitat

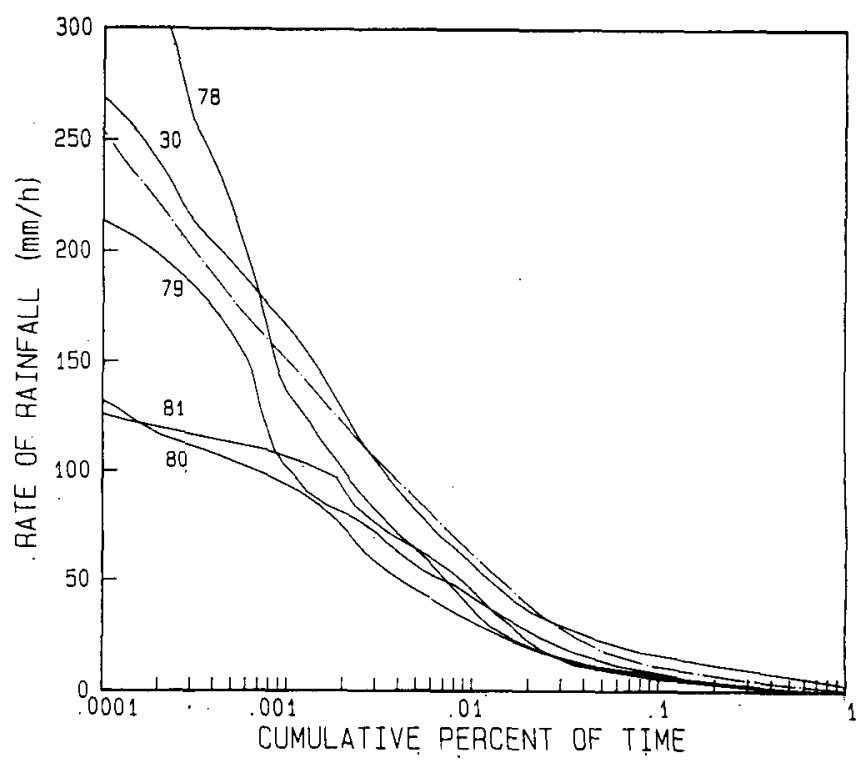

Fig. 16. Cumulative distributions of the years not considered in the study $(-\cdot-) 49$ years mean distribution.

Government of Catalonia and to the Spanish Advisory Committee for Scientific and Technical Research. The Portsmouth group is grateful to the British Council and to the Polytechnic. Special thanks are due to colleagues and students for the painful digitizing process, in particular, S. Alonso, $\mathbf{M}$. C. Llasat, and A. Redaño. Special thanks are also due to J. R. Norbury of RAL for useful information and to the Director of the Fabra Observatory, J. M. Codina, for the facilities and access to the Jardí recordings.

\section{REFERENCES}

[1] R. L. Olsen, D. V. Rogers, and D. B. Hodge, "The $a R^{b}$. relation in the calculation of rain attenuation," IEEE Trans. Ant. Propag., vol. AP26, no. 2 , pp. $318-329,1978$

[2] R: K. Crane, "Prediction of attenuation by rain," IEEE Trans. Commun., vol. COM-28, pp. 1717-1733, 1980.

[3] P. L. Rice and N. R. Holmberg, "Cumulative time statistics of surface point rainfall rates," IEEE Trans. Commun., vol. COM-21, pp. 1131-1136, 1973.

[4] H. T. Dougherty and E. J. Dutton, "Estimating year-to-year variability of rainfall for microwave applications," IEEE Trans. Commun., vol. COM-26, no. 8, pp. 1321-1324, 1978 .

[5] E. J. Dutton and H. T. Dougherty, "Year-to-year variability of rainfall for microwave applications in the U.S.," IEEE Trans. Commun., vol. COM-27, no. 5, pp. 829-832.

[6] CCIR, "Attenuation by hydrometeors in particular precipitation and other atmospheric particles," Rep. 721-1, Question 2/5, 1978-1982.

[7] B. N. Harden, J. R. Norbury, and W. J. K. White, "Measurements of rainfall for studies of millimetric radio attenuation," Microwaves Opt. Acoust., vol. 1, no. 6, pp. 197-202, 1977.

[8] J. R. Norbury, "A rapid response rain gauge for microwave attenuation studies," J. de Rech. At., vol. 8, pp. 245-251, 1972.

[9] S. H. Lin, "Dependence of rain-rate distribution on rain gauge integration time," Bell Syst. Tech. J., pp. 135-141, Jan. 1976.

[10] R. Jardí, "Un Pluviògraf d'Intensitats," Notes d'Estudi, Servei Meteorològic de Catalunya, vol. I, no. 2, pp. 3-10, Barcelona 1921.

[11] E. Fontseré, "Intensitats-pluviograph nach Jardi,", Meteor Zẹits., vol. 39, p. $89,1922$.

[12] R. Jardí, "Estudis de la Intensitat de la Pluja a Barcelona," Memòries de l'Institut d'Estudis Catalans, vol. I, Fasc. II, Barcelona, pp. 51-76, 1927.

[13] Handbook of Meteorological Instruments, Part I, Meteorological Office, London, England, 1956.

[14] W. E. K. Middleton and A. F. Spilhaus, Meteorological Instruments. Toronto, Canada: Univ. Toronto Press, 1953.

[15] A. Perlat and M. Petit, Measures en Meteorologie. Paris, France: Gauthier-Villars, 1961

[16] G. G. Rossman and J. M. Wardle, "The Hudson design-Jardí type 
recording rain intensity gauge and rainfall totaliser," Bull. Amer. Met. Soc., vol. 30, no. 3, pp. 97-103, 1949.

[17] CCIR: Recommendation AJ/5, Doc. 5/1033-E, September 1981, 15th Plenary Assembly, Geneva, Switzerland, 1982.

[18] L. Boithias, "On the statistical distribution of rain rate," Ann. des Télécomm., vol. 35, pp. 365-366, 1980.

[19] S. H. Lin, "Rain rate distributions and extreme value statistics," Bell Syst. Tech. J., vol. 55, no. 8, pp. 1111-1124, 1976.

[20] F. Fedi, "Attenuation due to rain on a terrestrial path," Alta Frequenza, vol. XLVIII, no. 4, pp. 167-184, 1979.

[21] - "Prediction of attenuation due to rainfall on terrestrial links," Radio Sci., vol. 16, no. 5, pp. 731-743, 1981.

[22] B. Segal, "An analytical examination of mathematical models for the rainfall rate distribution function." $A n n$. des Telecom., vol. 35, no. 11-12, pp. 434-438, 1980 .

[23] K. Morita, "Study of rain rate distribution," Rev. Electron. Commun. Labs., vol. 26, pp. 268-277, 1978.

[24] CCIR, "Radiometeorological data," Rep. 563-2, Question 2/5, 19741978-1982.

[25] J. De Reffye, "Modelisation mathematique des intensites de pluie en un point du sol," Rev. Statistique Appliquee, vol. XXX, no. 3, pp. 39$63,1982$.

[26] F. Moupfouma and J. De Reffye, "Empirical model for rainfall rate distribution," Electron. Lett., vol. 18, no. 11, pp. 460-461, 1982.

[27] _ "Two parameter empirical model for rainfall rate distribution," Electron. Lett., vol. 19, no. 19, pp. 800-801, 1983.

[28] T. J. Moulsley and E. Vilar, "Experimental and theoretical statistics of microwave amplitude scintillations on satellite down-links, " IEEE Trans. Ant. Propag., vol. AP-30, no. 6, pp. 1099-1106, 1982.

[29] B. Segal, "The estimation of worst month precipitation probabilities in microwave system design," Ann. des Télécomm., vol. 35, pp. 429433, 1980.

[30] M. Puigcerver, S. Alonso, J. Lorente, and E. Vilar, "Long-term precipitation rate statistics for north-east of spain," Electron. Lett., vol. 19 , no. 4 , pp. $129-130,1983$.

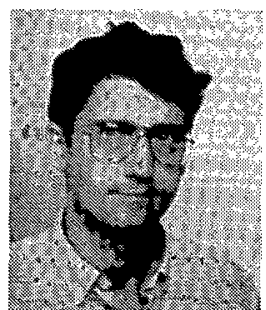

August Burgueño was born in Barcelona, Spain, in 1957. He received his meteorological education at the University of Barcelona, from which he received the degree in physics in 1981 .

He has completed his doctoral dissertation on rainfall rate statistics at that University, and in connection with that research, he has also worked in the Electrical and Electronic Engineering Department of Portsmouth Polytechnic (U.K.).

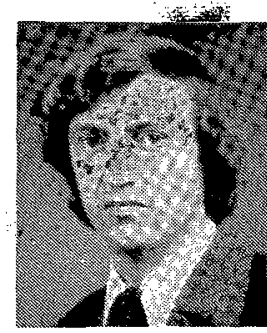

John Austin was born in Wiltshire, England and graduated with the first class honours degree in electrical and electronic engineering from Portsmouth Polytechnic in 1968 and the Ph.D. degree in electrical engineering in 1973.

$\mathrm{He}$ is currently a Senior:Lecturer at Portsmouth Polytechnic and a membersof the Microwave Telecommunications and Signal Processing Research Group. His main interests are computer systems and digital signal processing applied in a variety of disciplines.

Dr. Austin is a Chartered Engineer and a member of the Institution of Electrical Engineers (U.K.).

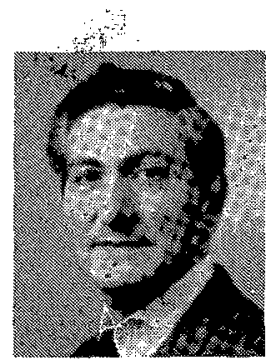

Enric Vilar was born in Barcelona, Spain. He graduated from the University of Barcelona with a degree in physics, and received the doctorate in electronics from the Institut d'Electronique Fondamentale, University of Paris, Paris, France, and the $\mathrm{Ph} . \mathrm{D}$. degree in electrical engineering from the University College, University of London, London, England.

He has held several responsible positions in industrial multinational and international organizations. In 1975, he joined Portsmouth Polytechnic, Portsmouth, England, where he is Professor of Telecommunication Systems and leads the Microwave Telecommunications and Signal Processing Research Unit, engaged in various aspects of microwave engineering and telecommunications systems in both terrestrial and satellite paths.

Prof. Vilar is a member of the British Institution of Electrical Engineers.

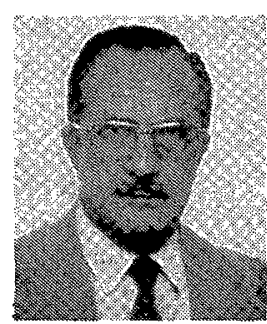

Manuel Puigcerver was born in Valencia, Spain, in 1922. He received the degree in physics from the University of Valencia in 1945 . He joined the Meteorological Service and was assigned to Barcelona Airport in 1950. While working there, he started work on his $\mathrm{Ph}$.D. dissertation and was also a part-time teaching assistant at the University of Barcelona. Because of a scholarship from the International Cooperation Administration of the U.S., he received the M.Sc. degree in meteorology from the University of Chicago in 1958. The University of Barcelona awarded him the Ph.D. degree in 1962.

He spent the whole year of 1961 at a Chilean Antarctic station as a meteorologist and scientific leader. He is Professor of Atmospheric Physics at the University of Barcelona since 1967 . He has published some 40 papers in scientific journals. He is presently interested in the synoptic and statistical aspects of high-intensity rainfall events.

Prof. Puigcerver is a member of the Royal Meteorological Society (U.K.), the American Meteorological Society, and the American Geophysical Union. 